\title{
A DENSITY FUNCTIONAL THEORY STUDY ON STRUCTURE AND PROPERTIES OF BENZENE AND BORAZINE-BASED CHROMOPHORES
}

\author{
REZA GHIASI*, SARA AKBARI \\ Department of Chemistry, East Tehran Branch, Qiam Dasht, Tehran, Islamic Azad University, IRAN
}

\begin{abstract}
Density functional theory (DFT) calculations were employed to investigate the structural characteristics, electronic properties, and nonlinear optical properties of borazine-based chromophores at B3LYP/ 6-311G(d,p) level. We studied the effects of various donor and acceptor substituents $(\mathrm{H}, \mathrm{F}, \mathrm{Cl}, \mathrm{Br}, \mathrm{Me}, \mathrm{NH}, \mathrm{OH}$, $\mathrm{COOH}, \mathrm{CHO}, \mathrm{CN}, \mathrm{NO}_{2}$ ) on the stability, dipole moment, polarizability, frontier orbitals, structure, the most intense electronic transition, and hyperpolarizabilities. These calculations indicate B-isomer is more stable than $\mathrm{N}$-isomer. On the other hand, the most stable isomer confirms the minimum polarizability and maximum hardness principles in the most molecules. Also, we obtained good linear relations between some of the studied properties. The predicted first hyperpolarizability also shows that the substituted molecules might have a reasonably good nonlinear optical (NLO) behavior.
\end{abstract}

Keywords: Borazine-Based Chromophores, Subsituent effect, Frontier orbitals analysis, Nonlinear optics.

\section{INTRODUCTION}

There is growing attention in materials with high non-linear optical (NLO) properties due to their potential application in technologies such as lasers, telecommunications, photovoltaic cells, organic light emitting diodes, and semiconductor layers in field-effect transistors [1] information processing and holography. Organic $\pi$-conjugated oligomers and polymers represent an excellent alternative to traditional inorganic NLO crystals because they can be easily synthesized and chemically modified. Extremely fast switching times, resistance to high intensity radiation, possibility of thin-layer fabrication, and low electric permittivity (related to low-frequency dependence in nonresonant regime) are important properties in favor of organic NLO materials. A variety of inorganic, organic, and organometallic molecular systems have been studied for NLO activity [2-10].

We report here on a systematic computational investigation of the NLO properties of borazine-based chromophores. The main purpose here is to assess the use of borazine moieties for the design of molecular NLO chromophores and to obtain insight into the structure-function relationships of these systems.

\section{Computational Methods}

All calculations were carried out with the Gaussian 03 suite of program [11]. All molecules were described by the standard $6-31 \mathrm{G}(\mathrm{d}, \mathrm{p})$ basis set [12-15]. Geometry optimization was performed using Becke's hybrid threeparameter exchange functional and the nonlocal correlation functional of Lee, Yang, and Parr (B3LYP) [16]. A vibrational analysis was performed at each stationary point which corresponds to an energy minimum.

Geometries were optimized at this level of theory without any symmetry constraints followed by the calculations of the first order hyperpolarizabilities. The total static first hyperpolarizability $\beta$ was obtained from the relation:

$$
\beta_{t o t}=\sqrt{\beta_{x}^{2}+\beta_{y}^{2}+\beta_{z}^{2}}
$$

upon calculating the individual static components

$$
\beta_{i}=\beta_{i i i}+\frac{1}{3} \sum_{i \neq j}\left(\beta_{i j j}+\beta_{j i j}+\beta_{j j i}\right)
$$

Due to the Kleinman symmetry [17]:

$$
\beta_{\mathrm{xyy}}=\beta_{\mathrm{yxy}}=\beta_{\mathrm{yyx}} ; \beta_{\mathrm{yyz}}=\beta_{\mathrm{yzy}}=\beta_{\mathrm{zyy}}, \ldots
$$

one finally obtains the equation that has been employed:

$\beta_{t o t}=\sqrt{\left(\beta_{x x x}+\beta_{x y y}+\beta_{x z z}\right)^{2}+\left(\beta_{y y y}+\beta_{y z z}+\beta_{y x x}\right)^{2}+\left(\beta_{z z z} z x x+\beta_{z y y}\right)^{2}}$
The electronic spectra for the studied compounds were calculated by TD-DFT [18] using the same hybrid functionals and basis sets as used for the calculation of the hyperpolarizabilities. The

10 lowest excitation energies were computed.

\section{RESULTS AND DISCUSSION}

\section{Energetic aspects}

Figure 1 shows benzene and borazine-Based chromophores investigated in this paper. Table 1 presents the computed energies, relative energies, for all molecules. The relative energies show that B-isomer is more stable than $\mathrm{N}$-isomer in all species. We believe the added stability of the B-isomer systems is due to the degree of polarization of the $\mathrm{B}-\mathrm{C}$ bond is greater than the N-F bond. For example, in $\mathrm{B}$-isomer $(\mathrm{X}=\mathrm{H})$ the charges on $\mathrm{B} 1$ and $\mathrm{C}^{2}$ ' are $+0.920 \mathrm{e}$ and $-0.480 \mathrm{e}$ respectively. In N-isomer, the charges on $\mathrm{N} 1$ and $\mathrm{C} 2$ ' are $-0.888 \mathrm{e}$ and +0.064 (Table 1). There is a good linear relation between the relative energies values and along with their Hammett constants $\left(\sigma_{p}\right)[19]$. (Figure2).<smiles>[X]C1=NSP(N=CN2B(C)N(C)B(C)N(C)B2C)C=N1</smiles>

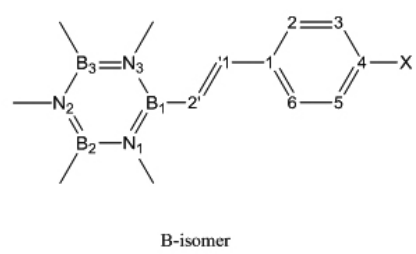<smiles>[Y]c1ccc(/C(C)=C(\C)B2NBN(CC)BN2)cc1</smiles>

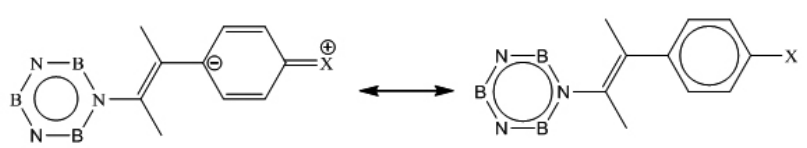

(I)

(II)

Figure 1. Resonance forms of Borazine-based chromophores with various X-groups. For acceptors, the zwitterionic form has the opposite charge separation. 
Table1. Absolute energy (Hartree), relative energy (kcal/mol), Hammet constant ( $\left.\boldsymbol{\sigma}_{\mathrm{p}}\right)$, dipole moment ( $\mu$, Debye) and NBO Charges of C2', N1, and B1 atoms of borazine-based chromophores with various X-groups.

\begin{tabular}{|c|c|c|c|c|c|c|c|c|c|c|}
\hline & \multicolumn{2}{|c|}{ Energy } & \multirow[b]{2}{*}{$\Delta \mathbf{E}$} & \multirow[b]{2}{*}{$\sigma_{p}$} & \multicolumn{2}{|c|}{$\mu_{\text {tot }}$} & \multicolumn{2}{|c|}{$\mathrm{N}$-isomer } & \multicolumn{2}{|c|}{ B-isomer } \\
\hline & N-isomer & B-isomer & & & N-isomer & B-isomer & $Q(C 2 ')$ & Q(N1) & $Q(C 2 ')$ & $\mathbf{Q}(\mathrm{B} 1)$ \\
\hline H & -551.261 & -551.287 & 16.01 & 0.00 & 1.62 & 1.13 & 0.064 & -0.888 & -0.480 & 0.920 \\
\hline $\mathbf{F}$ & -650.525 & -650.551 & 16.07 & 0.15 & 1.57 & 0.39 & 0.063 & -0.888 & -0.482 & 0.919 \\
\hline Cl & -1010.884 & -1010.909 & 15.71 & 0.24 & 2.05 & 1.05 & 0.070 & -0.887 & -0.473 & 0.919 \\
\hline $\mathrm{Br}$ & -3124.804 & -3124.829 & 15.68 & 0.23 & 1.97 & 0.93 & 0.065 & -0.891 & -0.459 & 0.918 \\
\hline OH & -626.504 & -626.531 & 16.70 & -0.38 & 3.21 & 2.28 & 0.053 & -0.888 & -0.494 & 0.920 \\
\hline $\mathrm{NH}_{2}$ & -606.634 & -606.661 & 17.19 & -0.57 & 3.89 & 3.83 & 0.046 & -0.889 & -0.506 & 0.919 \\
\hline Me & -590.589 & -590.615 & 16.28 & -0.14 & 1.97 & 1.74 & 0.060 & -0.888 & -0.486 & 0.920 \\
\hline $\mathrm{CN}$ & -643.528 & -643.552 & 14.81 & 0.70 & 5.25 & 4.39 & 0.087 & -0.884 & -0.454 & 0.917 \\
\hline $\mathrm{CF}_{3}$ & -888.402 & -888.426 & 15.15 & 0.53 & 5.24 & 2.41 & 0.082 & -0.885 & -0.461 & 0.918 \\
\hline СHO & -664.618 & -664.642 & 14.91 & 0.42 & 4.40 & 2.98 & 0.087 & -0.884 & -0.457 & 0.917 \\
\hline $\mathrm{COOH}$ & -739.894 & -739.918 & 15.11 & 0.44 & 3.09 & 1.55 & 0.084 & -0.884 & -0.461 & 0.917 \\
\hline $\mathrm{NO}_{2}$ & -755.820 & -755.843 & 14.48 & 0.81 & 5.69 & 4.65 & 0.094 & -0.883 & -0.447 & 0.916 \\
\hline
\end{tabular}

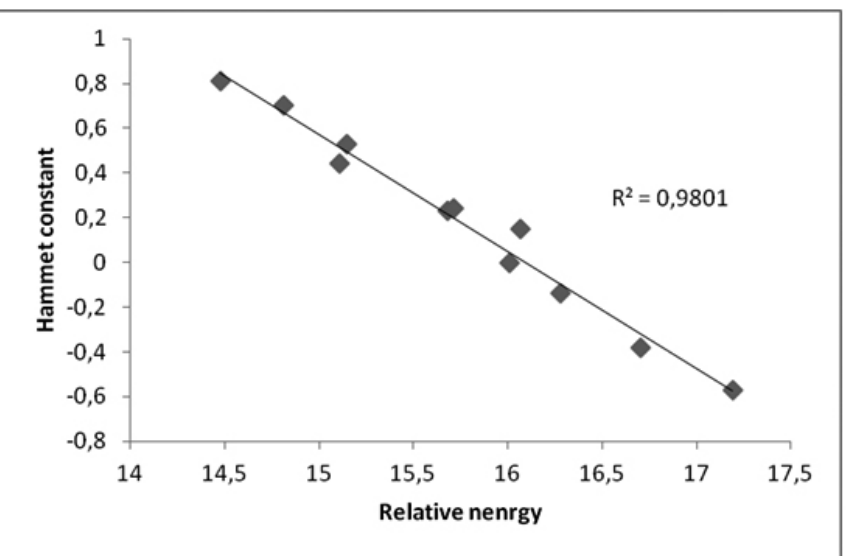
$\left(\sigma_{\mathrm{p}}\right)$.

Figure 2. Relative energy ( $\left.=\mathrm{E}^{\mathrm{N} \text {-isomer }}-\mathrm{E}^{\mathrm{B}-\text {-isomer }}\right)$ versus Hammett constants

\section{Dipole moment}

The dipole moment values have been gathered in Table 1. These values present $\mathrm{N}$-isomer has a larger dipole moment rather than B-isomer. A good correlation between $\mu$ and Hammett constants $\left(\sigma_{\mathrm{p}}\right)$ has been shown. See Figure 3 . As a consequence, dipole moment values also increases with an increase in the accepting strength of the X-group.

\section{Polarizability}

Polarizabilities describe the response of a system in an applied electric field [20]. They determine not only the strength of molecular interactions (such as the long range intermolecular induction, dispersion forces, etc.) as well as the cross sections of different scattering and collision processes, but also the nonlinear optical properties of the system [21].

The isotropic polarizability $\langle\alpha\rangle$ is calculated as the mean value as given in the following equation:

$$
<\alpha>=\frac{\left(\alpha_{x x}+\alpha_{y y}+\alpha_{z z}\right)}{3}
$$

And the polarizability anisotropy invariant is:

$$
\Delta \alpha=\left[\frac{\left(\alpha_{X X}-\alpha_{Y Y}\right)^{2}+\left(\alpha_{Y Y}-\alpha_{Z Z}\right)^{2}+\left(\alpha_{Z Z}-\alpha_{X X}\right)^{2}}{2}\right]^{\frac{1}{2}}
$$

The calculated isotropic and anisotropic polarizability values indicate these values decrease in the stable complexes, as expected from the principles of minimum energy and minimum polarizability in most cases (expect, $\mathrm{X}=\mathrm{NH}_{2}, \mathrm{OH}$; Table 2) [22]. On the other hand, there is a good correlation between isotropic and anisotropic polarizability values with relative energy values (Figure 4).
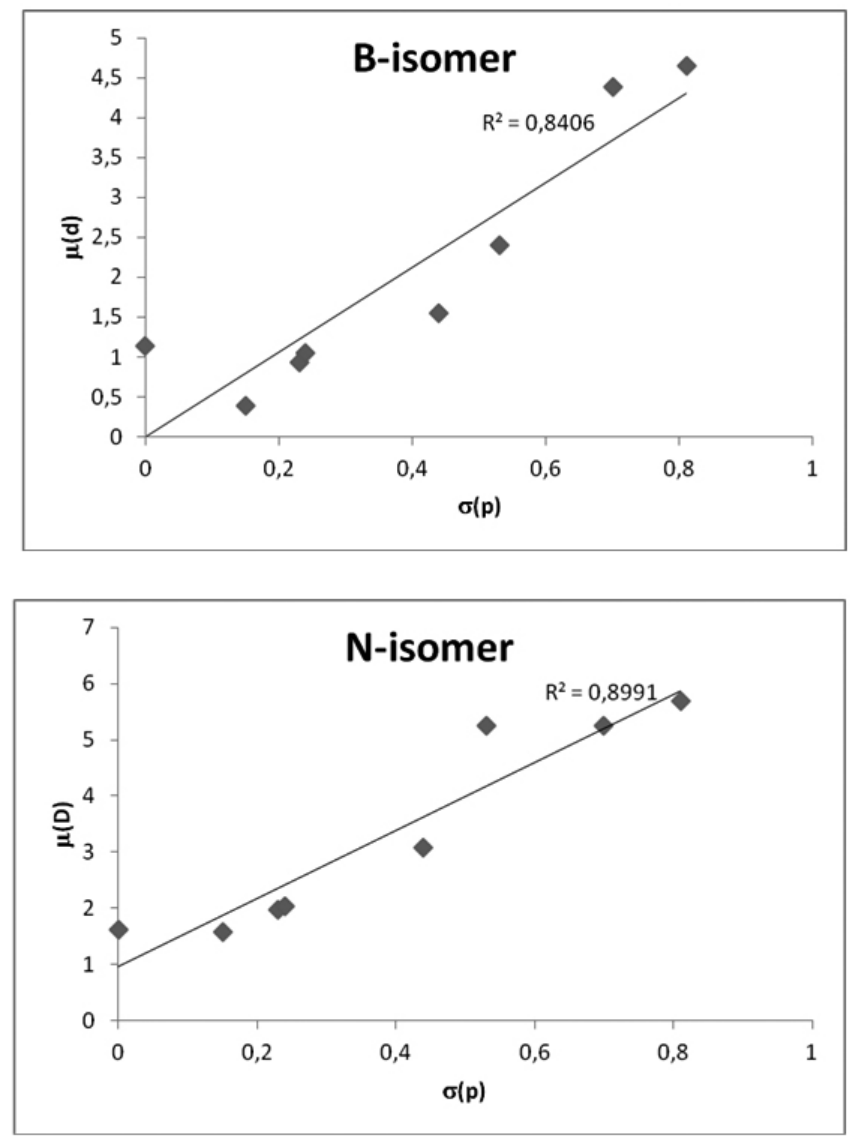

Figure 3. Dipole moment $(\mu)$ versus $\sigma p$ Hammett constants $(\sigma p)$. 
Table 2. Isotropic polarizability $<\alpha>$ and anisotropy polarizability $(\Delta \alpha)$ of borazine-based chromophores with various $\mathrm{X}$-groups.

N-isomer

\begin{tabular}{|c|c|c|c|c|c|}
\hline $\mathbf{X}$ & $\boldsymbol{\alpha x x}$ & $\boldsymbol{\alpha y y}$ & $\boldsymbol{\alpha z z}$ & $<\boldsymbol{\alpha}>$ & $\Delta \boldsymbol{\alpha}$ \\
\hline $\mathbf{H}$ & 260.787 & 139.702 & 73.940 & 158.14 & 164.16 \\
\hline $\mathbf{F}$ & 260.859 & 139.051 & 74.100 & 158.00 & 164.22 \\
\hline $\mathbf{C l}$ & 304.180 & 144.030 & 76.048 & 174.75 & 202.87 \\
\hline $\mathbf{B r}$ & 320.349 & 147.513 & 79.458 & 182.44 & 215.10 \\
\hline $\mathbf{O H}$ & 277.676 & 141.719 & 76.158 & 165.18 & 178.03 \\
\hline $\mathbf{N H}$ & 297.112 & 144.446 & 79.753 & 173.77 & 193.31 \\
\hline $\mathbf{M e}$ & 292.308 & 148.750 & 83.391 & 174.82 & 185.10 \\
\hline $\mathbf{C N}$ & 335.430 & 147.450 & 74.208 & 185.70 & 233.39 \\
\hline CF3 & 292.318 & 150.503 & 78.867 & 173.90 & 188.15 \\
\hline CHO & 331.835 & 155.859 & 73.325 & 187.01 & 228.70 \\
\hline COOH & 330.595 & 156.577 & 75.493 & 187.56 & 225.76 \\
\hline NO & 334.723 & 158.126 & 72.087 & 188.31 & 231.91 \\
\hline
\end{tabular}

\begin{tabular}{|c|c|c|c|c|c|}
\hline & $\boldsymbol{\alpha x x}$ & $\boldsymbol{\alpha y y}$ & $\boldsymbol{\alpha z z}$ & $<\boldsymbol{\alpha}>$ & $\Delta \boldsymbol{\alpha}$ \\
\hline $\mathbf{H}$ & 255.713 & 146.889 & 69.021 & 157.21 & 162.42 \\
\hline $\mathbf{F}$ & 257.317 & 146.220 & 69.067 & 157.53 & 163.91 \\
\hline $\mathbf{C l}$ & 298.592 & 150.047 & 72.492 & 173.71 & 199.00 \\
\hline $\mathbf{B r}$ & 314.962 & 153.435 & 75.963 & 181.45 & 211.20 \\
\hline OH & 278.632 & 149.437 & 70.213 & 166.09 & 182.22 \\
\hline NH & 304.095 & 152.919 & 72.381 & 176.47 & 203.75 \\
\hline Me & 289.339 & 155.586 & 78.542 & 174.49 & 184.74 \\
\hline CN & 317.687 & 150.197 & 75.197 & 181.03 & 215.03 \\
\hline CF3 & 278.756 & 153.745 & 79.259 & 170.59 & 174.61 \\
\hline CHO & 310.828 & 158.578 & 74.321 & 181.24 & 207.62 \\
\hline COOH & 312.534 & 160.044 & 75.681 & 182.75 & 207.93 \\
\hline NO & 307.255 & 160.322 & 74.236 & 180.60 & 204.08 \\
\hline
\end{tabular}

\section{Frontier orbital analysis}

A particularly interesting property for these molecules is the energy gap (E ) between the highest occupied molecular orbital (HOMO) and the lowest unoccupied molecular orbital (LUMO). The energy gap is considered as a reflection of the molecule's chemical activity. The frontier orbital energies values have been gathered in Table 3. These values display HOMO and LUMO energy values decrease in substituted molecules, except $\mathrm{X}=\mathrm{Me}, \mathrm{NH}_{2}, \mathrm{OH}$. Also, these values decrease in more stable isomer. Figure 5 presents linear correlation between frontier orbital energies and hammet constant values. A good correlation found suggests that the electron withdrawing/donating groups influences the $\mathrm{E}(\mathrm{HOMO})$, and this correlation may be used as a tool to predict $\mathrm{E}(\mathrm{HOMO})$ for other substituents for which $\sigma_{\mathrm{p}}$ is known. The same correlation is observed for $\mathrm{E}(\mathrm{LUMO})$ energies.

Table 3 exhibits the HOMO-LUMO gaps of all structures. These values indicate substitution causes decreasing of energy gaps. On the other hand, the calculated the HOMO-LUMO gaps values indicate these values increase in the stable isomer, as expected from the principles of minimum energy and maximum hardness in most cases (expect, $\mathrm{X}=\mathrm{NH}_{2}, \mathrm{OH}$; Table 3). There is a good correlation between relative hardness values with constant values (Figure $6)$.
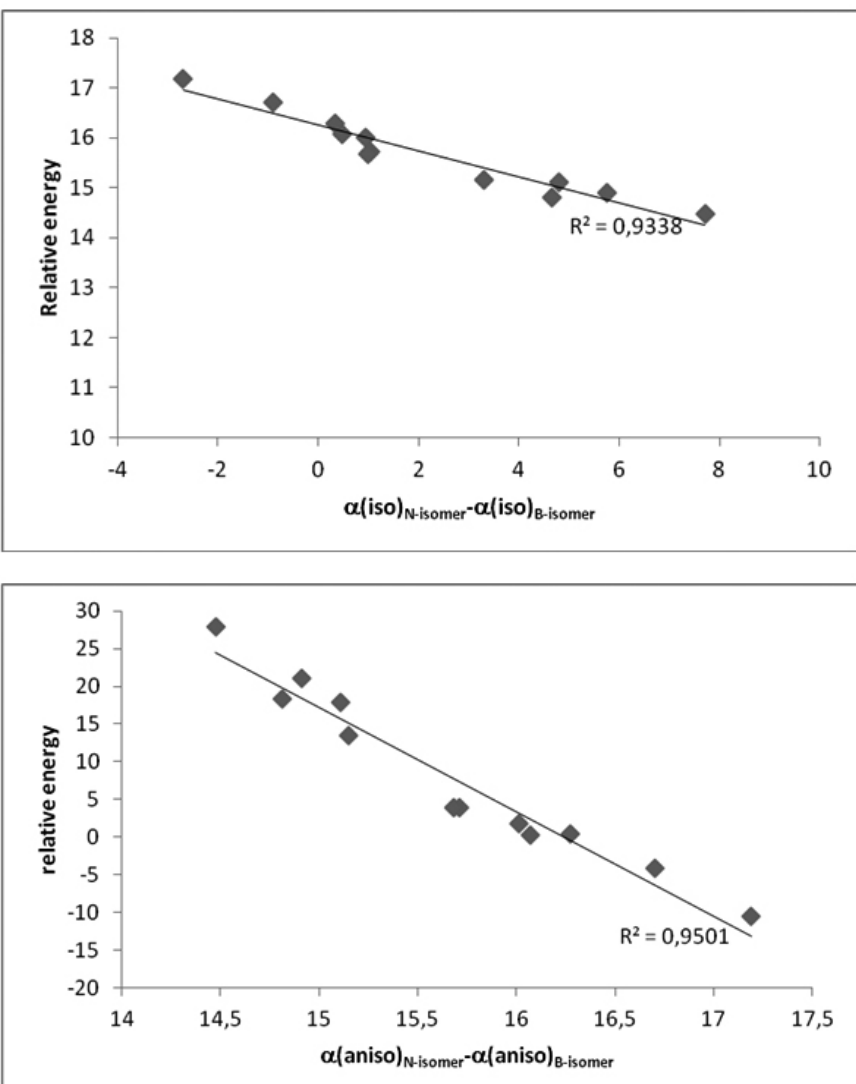

Figure 4. $\alpha(\text { iso })_{\mathrm{N}-\text { isomer }}-\alpha(\text { iso })_{\mathrm{B}-\text { isomer }}$ and $\alpha$ (aniso $)_{\mathrm{N} \text {-isomer }}-\alpha(\text { aniso })_{\mathrm{B}-\text { isomer }}$ values versus relative energy.

To evaluate the chemical potential $(\mu)$ of these complexes, these values can be calculated from the HOMO and LUMO orbital energies using the following approximate expression [23-29]:

$$
\mu=\frac{E_{H O M O}+E_{L U M O}}{2}
$$

The chemical potential characterizes the tendency of electrons to escape from the equilibrium system. As expected, more stable isomer has less chemical potential.

To evaluate the electrophilicity of these complexes, we have calculated the electrophilicity index, $\omega$, using the expression:

$$
\omega=\frac{\mu^{2}}{2 \eta}
$$

The values of electrophilicity index in Table 3 indicate more stable isomer has the largest electrophility.

\section{Structural analysis}

The optimized geometries of borazine-based chromophores studied in work with atom labeling are depicted in Figure 1. All studied molecules are essentially nonplanar. Table 4 shows the B3LYP/6-311G(d,p) selected structural data for the optimized structures with various $\mathrm{X}$-groups.

These values indicate bonds $\mathrm{C} 1 \mathrm{C} 2, \mathrm{C} 3 \mathrm{C} 4$, and $\mathrm{C} 5 \mathrm{C} 6$ are longer, while bonds B1N2 and B3N3 are shorter. These changes in the bond lengths indicate a larger contribution of the zwitterionic (nonaromatic) resonance structure to the ground state of these derivatives. 
Table 3. Frontier orbital energies (Hartree), HOMO-LUMO gap energy (eV), hardness (eV), and chemical potential (eV) for Borazine-Based Chromophores with Various X-Groups.

N-isomer

\begin{tabular}{|c|c|c|c|c|c|c|c|}
\hline & HOMO & LUMO & $\Delta \mathbf{E}$ & $\boldsymbol{\eta}$ & $\mathbf{S}$ & $\boldsymbol{\mu}$ & $\boldsymbol{\omega}$ \\
\hline $\mathbf{H}$ & -0.209 & -0.038 & 4.66 & 2.33 & 0.21 & -3.37 & 2.43 \\
\hline $\mathbf{F}$ & -0.211 & -0.040 & 4.65 & 2.32 & 0.22 & -3.42 & 2.51 \\
\hline $\mathbf{C l}$ & -0.214 & -0.047 & 4.54 & 2.27 & 0.22 & -3.55 & 2.78 \\
\hline $\mathbf{B r}$ & -0.214 & -0.048 & 4.52 & 2.26 & 0.22 & -3.55 & 2.79 \\
\hline $\mathbf{O H}$ & -0.198 & -0.031 & 4.53 & 2.26 & 0.22 & -3.11 & 2.14 \\
\hline $\mathbf{N H}_{2}$ & -0.185 & -0.026 & 4.35 & 2.17 & 0.23 & -2.87 & 1.90 \\
\hline $\mathbf{M e}$ & -0.204 & -0.035 & 4.60 & 2.30 & 0.22 & -3.26 & 2.31 \\
\hline $\mathbf{C N}$ & -0.225 & -0.070 & 4.24 & 2.12 & 0.24 & -4.01 & 3.80 \\
\hline $\mathbf{C F}$ & -0.222 & -0.057 & 4.50 & 2.25 & 0.22 & -3.80 & 3.21 \\
\hline $\mathbf{C H O}_{3}$ & -0.221 & -0.074 & 4.02 & 2.01 & 0.25 & -4.01 & 4.00 \\
\hline $\mathbf{C O O H}$ & -0.219 & -0.065 & 4.20 & 2.10 & 0.24 & -3.86 & 3.54 \\
\hline $\mathbf{N O}$ & -0.230 & -0.092 & 3.76 & 1.88 & 0.27 & -4.38 & 5.10 \\
\hline
\end{tabular}

B-isomer

\begin{tabular}{|c|c|c|c|c|c|c|c|}
\hline & HOMO & LUMO & $\Delta \mathbf{E}$ & $\boldsymbol{\eta}$ & $\mathbf{S}$ & $\boldsymbol{\mu}$ & $\boldsymbol{\omega}$ \\
\hline $\mathbf{H}$ & -0.231 & -0.059 & 4.68 & 2.34 & 0.21 & -3.94 & 3.31 \\
\hline $\mathbf{F}$ & -0.232 & -0.061 & 4.65 & 2.33 & 0.21 & -3.98 & 3.40 \\
\hline $\mathbf{C l}$ & -0.235 & -0.067 & 4.56 & 2.28 & 0.22 & -4.10 & 3.69 \\
\hline $\mathbf{B r}$ & -0.233 & -0.067 & 4.52 & 2.26 & 0.22 & -4.09 & 3.70 \\
\hline $\mathbf{O H}$ & -0.216 & -0.051 & 4.47 & 2.24 & 0.22 & -3.64 & 2.95 \\
\hline $\mathbf{N H}_{2}$ & -0.200 & -0.045 & 4.23 & 2.11 & 0.24 & -3.34 & 2.64 \\
\hline $\mathbf{M e}$ & -0.224 & -0.055 & 4.60 & 2.30 & 0.22 & -3.80 & 3.15 \\
\hline $\mathbf{C N}$ & -0.248 & -0.087 & 4.38 & 2.19 & 0.23 & -4.57 & 4.76 \\
\hline $\mathbf{C F}$ & -0.246 & -0.076 & 4.63 & 2.32 & 0.22 & -4.38 & 4.14 \\
\hline $\mathbf{C H O}$ & -0.244 & -0.089 & 4.22 & 2.11 & 0.24 & -4.54 & 4.89 \\
\hline $\mathbf{C O O H}$ & -0.242 & -0.081 & 4.37 & 2.18 & 0.23 & -4.40 & 4.43 \\
\hline $\mathbf{N O}$ & -0.255 & -0.105 & 4.07 & 2.03 & 0.25 & -4.89 & 5.89 \\
\hline
\end{tabular}

\section{Electronic spectra}

We found the most intense electronic transition $\left(\lambda_{\text {max }}\right)$ of molecules. The wavelength, oscillator strength and the composition of the transitions obtained by TD-DFT calculations are given in Table 5 . The most intense electronic transition for all molecules is attributed to HOMO ${ }^{\circledR L} L \mathrm{UMO}$ transition. The $\lambda$ is a function of substituent, the stronger the donor character of substituent, the more electron push into the molecule, the less $\lambda$. These calculations illustrate the decreasing of $\lambda_{\max }$ in B-isomer, which is compatible with larger HOMOLUMO gap in this isomer. There is a good correlation between HOMO-LUMO gap and $\lambda_{\max }$ (Figure 7).

\section{Hyperpolarizability}

The first static hyperpolarizability $\left(\beta_{\text {tot }}\right)$ values for the all molecules are shown in Table 6 . The results show that the magnitude of the first hyperpolarizability tensor of all molecules is rather moderate, and $\mathrm{NO}_{2}$ and $\mathrm{NH}_{2}$ substations have the most value in $\mathrm{N}$ - and B-isomers, respectively. Also, these values indicate the first hyperpolarizability values of $\mathrm{N}$-isomer are more than B-isomer with withdrawing substitutions. On the other hand, these values of $\mathrm{N}$-isomer are less than $\mathrm{B}$-isomer with donor substitutions.

This chromophore exhibits larger non-linearity and its $\lambda_{\text {max }}$ is red-shifted in $\mathrm{B}$-isomers (except $\beta$ in $\mathrm{X}=\mathrm{Me}, \mathrm{CN}$ ) and $\mathrm{N}$-isomers when compared with unsubstituted molecule. Therefore, it is clear that the hyperpolarizability is a strong function of the absorption maximum. Since even a small absorption at the operating wavelength of optic devices can be detrimental, it is important to make NLO chromophores as transparent as possible without compromising the molecule's non-linearity.

A good correlation has been shown between $\beta_{\text {tot }}$ and $\lambda_{\max }$ in $\mathrm{N}$-isomer for all substituents (Figure 8). But, there is similar correlation in $\mathrm{B}$-isomer for donor substituents and withdrawing substituents.

\section{CONCLUSION}

The study of electronic, structural and spectroscopic properties as well as the static first hyperpolarizabilities of the borazine-based chromophores indicated stability of B-isomer species is more than $\mathrm{N}$-isomer. The decreasing of isotropic and anisotropic polarizability values and increasing of HOMOLUMO gaps values in the stable complexes is compatible with the principles of minimum energy and minimum polarizability in most cases (expect, $\mathrm{X}=\mathrm{NH}_{2}$, $\mathrm{OH})$. Calculations showed that the most intense electronic transition is due to $\mathrm{HOMO} \rightarrow$ LUMO transition in all molecules. Theoretical studies indicated acceptor substitutions causes to increasing the first hyperpolarizability values in $\mathrm{N}$-isomer rather than $\mathrm{B}$-isomer, whist, these values of $\mathrm{N}$-isomer are less than B-isomer with donor substitutions. 
Table 4. Optimized Bond lengths $(\AA)$ of Borazine-Based Chromophores with Various X-Groups.

$\mathrm{N}$-isomer

\begin{tabular}{|c|c|c|c|c|c|c|c|c|c|c|c|c|c|c|c|}
\hline$X$ & $1 \mathrm{B1}$ & $31 N 2$ & $2 B 2$ & B2N3 & N3B3 & $33 N 1$ & N1C2' & C1'C2' & C1'C1 & C1C2 & $\mathrm{C} 2 \mathrm{C3}$ & $\mathrm{C3C} 4$ & C4C5 & C5C6 & $\mathrm{C6C1}$ \\
\hline H & & & & & & & & & & & & & 395 & 389 & 406 \\
\hline F & (T) & 67 & T20 & 429 & 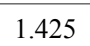 & & 717 & עד & 700 & 405 & .391 & 385 & 1.388 & .389 & .406 \\
\hline $\mathrm{Cl}$ & & 1 & 1.42 & 0 & & & & & & & 390 & 389 & 92 & & .406 \\
\hline $\mathrm{Br}$ & TTO & 1.425 & 1.420 & 1.429 & 1.424 & 1.770 & 1.415 & 1.071 & 1.700 & 1.400 & 1.071 & 1.390 & 1.392 & 1.509 & 1.406 \\
\hline OH & 444 & 1.425 & 1.428 & 1.428 & 1.426 & 1.446 & 1.420 & 1.340 & 1.467 & 1.403 & 1.391 & 1.394 & 1.398 & .386 & 1.408 \\
\hline $\mathbf{N H}_{2}$ & 1413 & 1.425 & 1.428 & 1.428 & 1.427 & 945 & 1.421 & 1.340 & 1.466 & 1.404 & 1.388 & 2 & 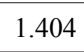 & 6 & .406 \\
\hline Me & 1444 & 1425 & 1428 & 1420 & 1425 & 1446 & 1418 & 1340 & 1467 & 1402 & 1392 & 1.396 & 1.402 & 1.387 & 1.407 \\
\hline $\mathrm{CN}$ & 1.448 & 1.422 & 1.428 & 1.430 & 1.422 & 1.450 & 1.411 & 1.343 & 1.463 & 1.407 & 1.386 & 1.402 & 1.405 & .384 & 1.409 \\
\hline $\mathrm{CF}_{3}$ & 1.447 & 1.423 & 1.428 & 1.430 & 1.423 & 1.449 & 1.413 & 1.342 & 1.465 & 1.405 & 1.389 & 1.393 & 1.397 & 1.386 & 1.408 \\
\hline CHO & 1.448 & 1.422 & 1.428 & 1.430 & 1.423 & 1.450 & .412 & 1.343 & 1.462 & $1.40^{\circ}$ & 1.388 & 397 & 1.404 & .381 & 1.413 \\
\hline $\mathrm{COOH}$ & 1.447 & 1.423 & 1.428 & 1.430 & 1423 & 1.449 & 1413 & 1242 & 1.464 & 1407 & 1387 & 1.398 & 1.401 & 1.383 & 1.409 \\
\hline $\mathrm{NO}_{2}$ & 1.449 & 1.422 & 1.428 & 1.430 & 1.422 & 1.451 & 1.410 & 1.343 & 1.462 & 1.409 & 1.386 & 1.391 & 1.394 & 1.384 & 1.410 \\
\hline
\end{tabular}

\section{B-isomer}

\begin{tabular}{|c|c|c|c|c|c|c|c|c|c|c|c|c|c|c|c|}
\hline $\mathrm{X}$ & $1 \mathrm{~N} 1$ & V1B2 & B2N2 & N2B3 & B3N3 & N3B1 & B1C2, & C1'C2' & $\mathrm{C} 1^{\prime} \mathrm{C} 1$ & C1C2 & $\mathrm{C} 2 \mathrm{C} 3$ & $\mathrm{C3C} 4$ & C4C5 & C5C6 & $\mathrm{C6C1}$ \\
\hline H & 439 & 428 & 429 & 430 & 427 & 1.438 & 1.559 & 1.345 & 469 & 1.404 & 1.391 & 1.392 & 1.396 & 1.388 & 1.406 \\
\hline F & +50 & $1.4 \angle 0$ & 29 & 1.450 & 1.421 & 1.450 & 1.359 & 1.545 & 1.409 & 1.404 & 1.391 & 1.385 & 1.389 & 1.387 & 1.406 \\
\hline $\mathrm{Cl}$ & 438 & 1.428 & 1.429 & 1.430 & 1.427 & 1.438 & 1.560 & .345 & 469 & .403 & 1.391 & 1.389 & 1.393 & 1.387 & 1.405 \\
\hline $\mathrm{Br}$ & 438 & 428 & 1.429 & 1.430 & .427 & 1.438 & 560 & 1.345 & 469 & .403 & 1.391 & 1.390 & 1.394 & 1.388 & 1.405 \\
\hline OH & 1.440 & 1.427 & 1.430 & 1.430 & 1.426 & 1.440 & 1.557 & 1.346 & 1.466 & 1.402 & 1.390 & 1.395 & 1.400 & 1.384 & 1.408 \\
\hline $\mathrm{NH}_{2}$ & 1441 & 1.426 & 430 & .431 & .425 & 1 & 1.555 & 1.348 & 463 & 1.405 & 1.387 & 1.403 & 1.407 & 1.383 & 1.407 \\
\hline Me & 1.439 & 1.427 & 1.429 & 1.430 & 1.426 & 1.439 & 1.558 & 1.346 & 1468 & 1.402 & 1.392 & 1.396 & 1.403 & 1.386 & 1.406 \\
\hline $\mathrm{CN}$ & 1.436 & 1.429 & 1.429 & 1.430 & 1.428 & 1.436 & 1.563 & 1.345 & 1.469 & 1.405 & 1.387 & 1.401 & 1.405 & 1.384 & 1.406 \\
\hline $\mathrm{CF}_{3}$ & 1.437 & 1.429 & 1.429 & 1.430 & 1.428 & 1.437 & 1.562 & 1.344 & 1.470 & 1.403 & 1.390 & 1.393 & 1.398 & 1.385 & 1.406 \\
\hline CHO & 1.437 & 1.429 & 1.429 & 1.430 & 1.428 & 1.437 & 1.562 & 1.345 & 1.468 & 1.405 & 1.389 & 1.397 & 1.403 & 1.382 & 1.410 \\
\hline $\mathrm{COOH}$ & 1.437 & 1.429 & 1.429 & 1.430 & 1.428 & 1.437 & 1.562 & 1.345 & 1.469 & 1.405 & 1.3 & 1.398 & 1.401 & 1.384 & 1.407 \\
\hline $\mathrm{NO}_{2}$ & 1.436 & 1.480 & 1.429 & 1.430 & 1.429 & 1.436 & 1.564 & 1.345 & 1.469 & 1.406 & 1.388 & 1.390 & 1.393 & 1.388 & 1.407 \\
\hline
\end{tabular}

Table 5. Maximum Absorption wavelength $\left(\lambda_{\max }\right)$, Oscillator strength (f), and its character for borazine-based chromophores with various X-groups.

\begin{tabular}{|c|c|c|c|c|c|}
\hline & \multirow[b]{2}{*}{ character } & \multicolumn{2}{|c|}{ N-isomer } & \multicolumn{2}{|c|}{ B-isomer } \\
\hline & & $\lambda_{\max }$ & $\mathbf{f}$ & $\lambda_{\max }$ & f \\
\hline $\mathbf{H}$ & $\mathrm{HOMO} \rightarrow$ LUMO & 286.95 & 0.6877 & 277.81 & 0.8117 \\
\hline $\mathbf{F}$ & $\mathrm{HOMO} \rightarrow \mathrm{LUMO}$ & 288.60 & 0.5803 & 279.87 & 0.7579 \\
\hline Cl & $\mathrm{HOMO} \rightarrow \mathrm{LUMO}$ & 294.37 & 0.7667 & 286.60 & 0.8986 \\
\hline $\mathrm{Br}$ & $\mathrm{HOMO} \rightarrow$ LUMO & 296.29 & 0.8082 & 290.02 & 0.9224 \\
\hline OH & $\mathrm{HOMO} \rightarrow$ LUMO & 296.39 & 0.5979 & 290.45 & 0.8057 \\
\hline $\mathrm{NH}_{2}$ & $\mathrm{HOMO} \rightarrow \mathrm{LUMO}$ & 308.24 & 0.6218 & 306.66 & 0.8390 \\
\hline Me & $\mathrm{HOMO} \rightarrow \mathrm{LUMO}$ & 290.82 & 0.7622 & 283.37 & 0.9175 \\
\hline $\mathrm{CN}$ & $\mathrm{HOMO} \rightarrow \mathrm{LUMO}$ & 309.30 & 0.9708 & 295.71 & 0.9774 \\
\hline $\mathrm{CF}_{3}$ & $\mathrm{HOMO} \rightarrow \mathrm{LUMO}$ & 294.60 & 0.8166 & 281.36 & 0.8660 \\
\hline CHO & $\mathrm{HOMO} \rightarrow \mathrm{LUMO}$ & 323.59 & 0.9312 & 306.52 & 0.9179 \\
\hline $\mathrm{COOH}$ & $\mathrm{HOMO} \rightarrow \mathrm{LUMO}$ & 313.42 & 0.9459 & 298.05 & 0.9504 \\
\hline $\mathrm{NO}_{2}$ & $\mathrm{HOMO} \rightarrow \mathrm{LUMO}$ & 352.16 & 0.6839 & 326.03 & 0.6617 \\
\hline
\end{tabular}



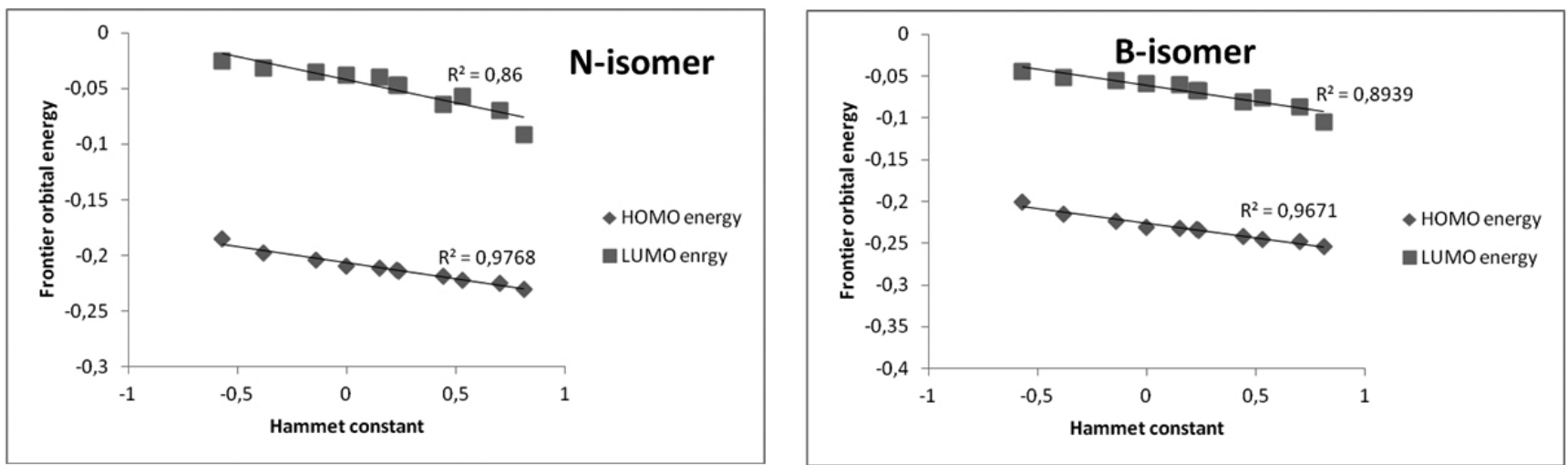

Figure 5. Frontier orbital values versus relative energy.
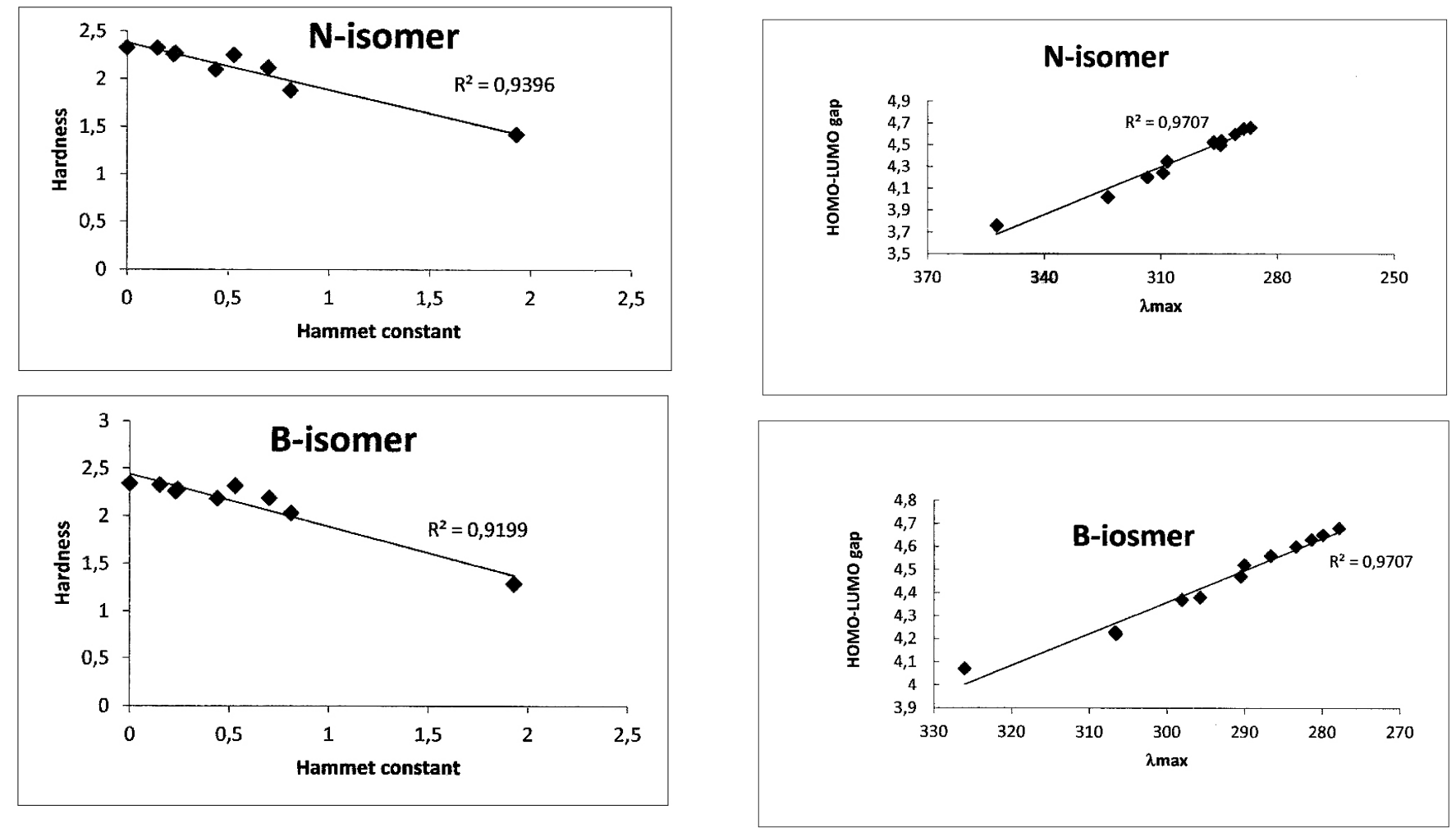

(a)

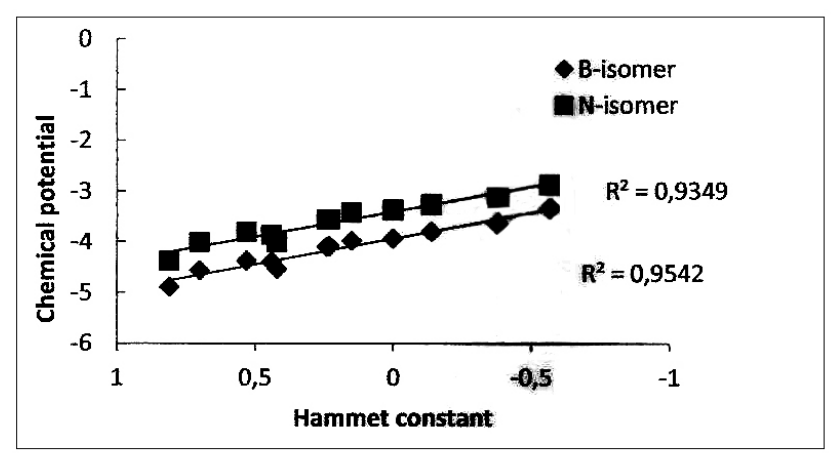

Figure 7. HOMO-LUMO gap versus $\lambda_{\max }$.

\section{(b)}

Figure 6. (a)Hardness (except for $\mathrm{Me}, \mathrm{NH}_{2}, \mathrm{OH}$ ) and (b) chemicalpotential values versus hammet constant. 
J. Chil. Chem. Soc., 59, № 4 (2014)

Table 6. $\beta$ components and $\beta_{\text {tot }}$ values $\left(10^{-30} \mathrm{esu}\right)$ for Borazine-Based Chromophores with Various X-Groups.

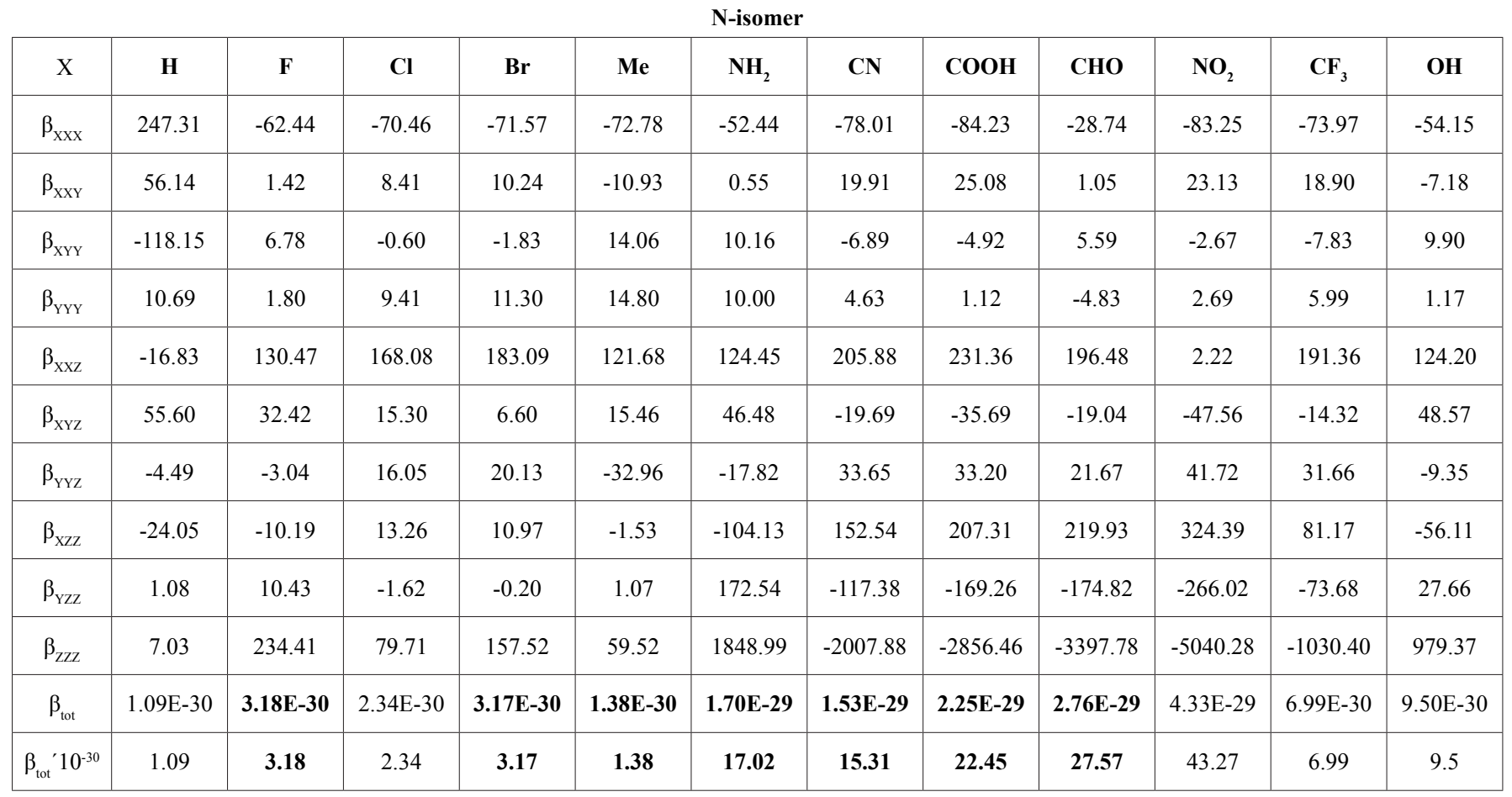

\begin{tabular}{|c|c|c|c|c|c|c|c|c|c|c|c|c|}
\hline \multicolumn{13}{|c|}{ B-isomer } \\
\hline $\mathrm{X}$ & H & $\mathbf{F}$ & Cl & $\mathrm{Br}$ & Me & $\mathrm{NH}_{2}$ & $\mathbf{C N}$ & СОOH & CHO & $\mathrm{NO}_{2}$ & $\mathbf{C F}_{3}$ & $\mathbf{O H}$ \\
\hline$\beta_{\mathrm{xxx}}$ & 27.92 & 26.61 & 21.49 & 20.99 & 29.33 & 57.02 & 15.42 & 4.93 & 68.14 & 3.67 & 10.33 & 48.85 \\
\hline$\beta_{\mathrm{XXY}}$ & -9.91 & -13.85 & -11.08 & -10.08 & -33.26 & -24.01 & -6.88 & -1.79 & -25.08 & -4.08 & -7.31 & -21.73 \\
\hline$\beta_{\mathrm{XYY}}$ & 4.12 & 1.54 & -0.66 & 0.10 & 10.95 & 7.76 & -1.39 & 3.56 & 14.93 & 3.49 & 1.20 & 4.83 \\
\hline$\beta_{\mathrm{xxz}}$ & -42.46 & -46.68 & -19.80 & -7.01 & -63.98 & -78.85 & -6.25 & 20.84 & -24.35 & 22.80 & 0.61 & -65.60 \\
\hline$\beta_{\mathrm{XYZ}}$ & 22.02 & 30.45 & 21.38 & 13.69 & 22.40 & 35.23 & 14.20 & 0.84 & 23.86 & -1.27 & 14.17 & 39.39 \\
\hline$\beta_{\mathrm{YYZ}}$ & 17.17 & 21.99 & 33.30 & 37.40 & -13.14 & 32.28 & 43.58 & 47.38 & 30.67 & 47.21 & 41.22 & 24.84 \\
\hline$\beta_{\mathrm{zzz}}$ & 702.19 & 1222.74 & 1411.03 & 1642.97 & 1291.75 & 3344.65 & -265.34 & -959.81 & -1360.79 & -2515.21 & 192.77 & 2159.49 \\
\hline$\beta_{\text {tot }}$ & $5.87 \mathrm{E}-30$ & $1.04 \mathrm{E}-29$ & $1.24 \mathrm{E}-29$ & $1.45 \mathrm{E}-29$ & $1.05 \mathrm{E}-29$ & $2.87 \mathrm{E}-29$ & $2.06 \mathrm{E}-30$ & $7.83 \mathrm{E}-30$ & $1.19 \mathrm{E}-29$ & $2.13 \mathrm{E}-29$ & $2.03 \mathrm{E}-30$ & $1.84 \mathrm{E}-29$ \\
\hline$\beta_{\text {tot }} \times 10^{-30}$ & 5.87 & 10.4 & 12.36 & 14.52 & 10.53 & 28.7 & 2.06 & 7.83 & 11.93 & 21.28 & 2.03 & 18.37 \\
\hline
\end{tabular}



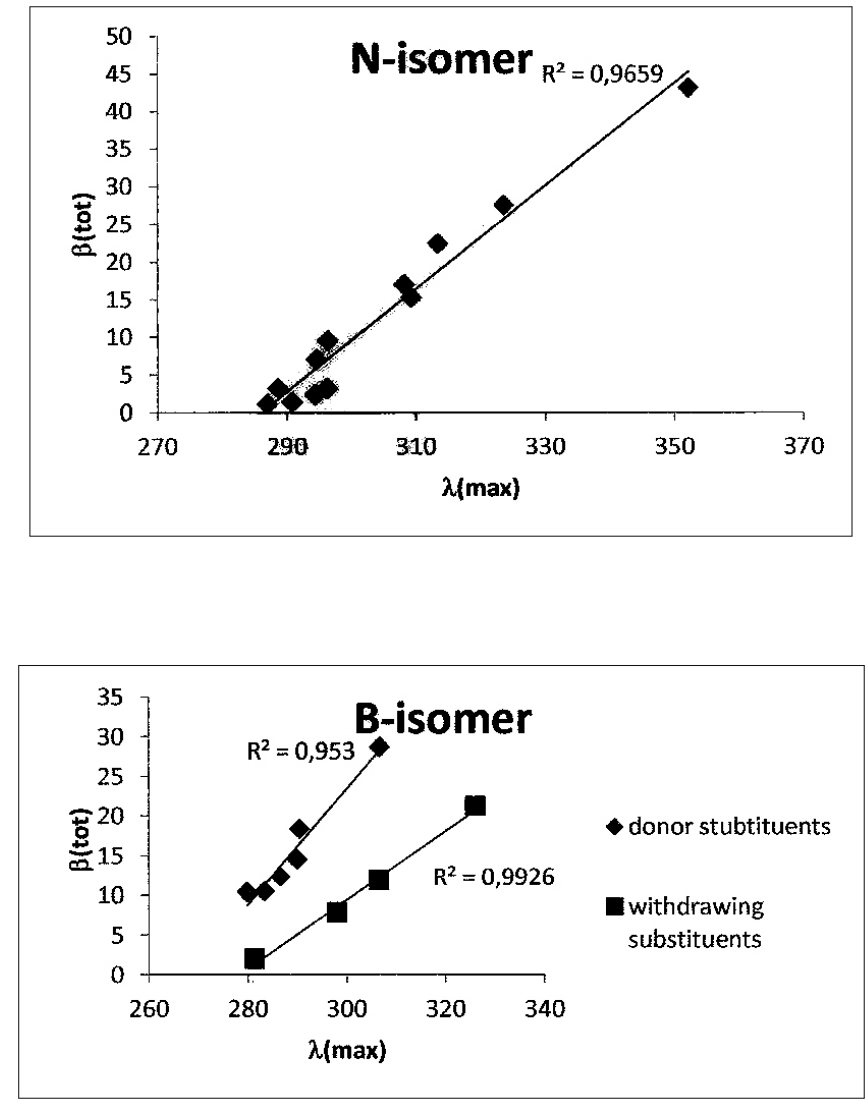

Figure 8. The first static hyperpolarizability $\left(\beta_{\text {tot }}\right)$ versus $\lambda_{\text {max }}$.

\section{REFERENCES}

1. C.D. Dimitrakopolous, P. Malenfant, Adv. Mater. 14, 29, (2002).

2. D.R. Kanis, M.A. Ratner, T.J. Marks, Chem. Rev 94, 195, (1994).

3. P.J. Mendes, T.J.L. Silva, A.J.P. Carvalho, J.P.P. Ramalho, Journal of Molecular Structure: THEOCHEM 946, 33,

4. D. Avc1, A. Basoglu, Y. Atalay, Struct Chem 21, 213, (2010).

5. M. Medved, S. Budzák, I. Cernušák, Journal of Molecular Structure: THEOCHEM 961, 66, (2010).

6. W. Bartkowiak, K. Strasburger, Journal of Molecular Structure: THEOCHEM 960, 93, (2010).

7. L.A.D. Souza, A.M.D.S. Jr., G.M.A. Junqueira, A.C.M. Carvalho, H.F.D Santos, Journal of Molecular Structure: THEOCHEM 959, 92, (2010).

8. A. Karton, M.A. Iron, M.E.v.d. Boom, J.M.L. Martin, J. Phys. Chem. A 109, 5454, (2005).

9. P.C. Ray, Chemical Physics Letters 354, (2004).

10. A. Hameed, A. Rybarczyk-Pirek, J. Zakrzewski, Journal of Organometallic Chemistry 656, 102, (2002).

11. M.J. Frisch, G.W. Trucks, H.B. Schlegel, G.E. Scuseria, M.A. Robb, J.R Cheeseman, J.A. Montgomery, Jr., T. Vreven, K.N. Kudin, J.C. Burant, J.M. Millam, S.S. Iyengar, J. Tomasi, V. Barone, B. Mennucci, M. Cossi, G. Scalmani, N. Rega, G.A. Petersson, H. Nakatsuji, M. Hada, M. Ehara, K. Toyota, R. Fukuda, J. Hasegawa, M. Ishida, T. Nakajima, Y. Honda, O. Kitao, H. Nakai, M. Klene, X. Li, J.E. Knox, H.P. Hratchian, J.B. Cross, C. Adamo, J. Jaramillo, R. Gomperts, R.E. Stratmann, O. Yazyev, A.J. Austin, R. Cammi, C. Pomelli, J.W. Ochterski, P.Y. Ayala, K. Morokuma, G.A. Voth, P. Salvador, J.J. Dannenberg, V.G. Zakrzewski, S. Dapprich, A.D. Daniels, M.C. Strain, O. Farkas, D.K. Malick, A.D. Rabuck, K. Raghavachari, J.B. Foresman, J.V. Ortiz, Q. Cui, A.G. Baboul, S. Clifford, J. Cioslowski, B.B. Stefanov, G. Liu, A. Liashenko, P. Piskorz, I. Komaromi, R.L. Martin, D.J. Fox, T. Keith, M.A. Al-Laham, C.Y. Peng, A. Nanayakkara, M. Challacombe, P.M.W. Gill, B. Johnson, W. Chen, M.W. Wong, C. Gonzalez, J.A. Pople, Gaussian 03, Gaussian, Inc., Pittsburgh PA,2003.

12. M.J.S. Dewar, C.H. Reynolds, J. Comp. Chem. 2, 140, (1986).

13. K. Raghavachari, J.A. Pople, E.S. Replogle, M. Head-Gordon, J. Phys. Chem. A 94, 5579, (1990).

14. A.D. McLean, G.S. Chandler, J. Chem. Phys. 72, 5639, (1980).

15. R. Krishnan, J.S. Binkley, R. Seeger, J.A. Pople, J. Chem. Phys. 72, 650, (1980).

16. A.D. Becke, J. Chem. Phys 98, 5648, (1993).

17. D.A. Keleiman, Phy. Rev. 126, 1977, (1962).

18. E. Runge, E.K.U. Gross, Phys. Rev. Lett. 52, 997, (1984).

19. C. Hansch, A. Leo, R.W. Taft, Chem. Rev. 97, 165, (1991).

20. C.R. Zhang, H.S. Chen, G.H. Wang, Chem. Res. Chinese 20, 640, (2004).

21. H. Cheng, J. Feng, A. Ren, J. Liu, Acta Chim. Sin. 60, 830, (2002).

22. D.R. Roy, P.K.r. Chattaraj, J. Phys. Chem. A 112, 1612, (2008).

23. P. Geerlings, F.D. Proft, W. Langenaeker, Chem. Rev. 103, 1793, (2003).

24. H. Chermette, J. Comput. Chem. 20, 129, (1999).

25. C.-G. Zhan, J.A. Nichols, D.A.J. Dixon, J. Phys. Chem. A 107, 4184, (2006).

26. R.G. Parr, Z. Zhou, Acc. Chem. Res. 26, 256, (1993).

27. L.G. Arnaut, S.J. Formosinho, Chem. Eur. J. 14, 6578, (2008).

28. R.G. Pearson, J. Chem. Educ. 64, 561, (1987).

29. R.G. Parr, P.K. Chattaraj, J. Am. Chem. Soc. 113, 1854, (1991). 